\title{
THE EFFECT OF CARBIDE DECOMPOSITION AND REFORMATION ON RUPTURE LIVES OF IN738LC DURING MULTIPLE REHEAT TREATMENT AND DEGRADATION CYCLES
}

\author{
S. Pahlavanyali ${ }^{1 *}$, M Wood $^{1}$, G. Marchant ${ }^{2}$ \\ 1) ERA Technology, Cleeve Road, Leatherhead, KT22 7SA, UK \\ 2) Siemens Industrial Turbomachinery, Waterside South, Lincoln LN5 7FD, UK
}

Keywords: IN738LC, Repair, Heat treatment, Rupture life, Carbide

\begin{abstract}
The subject of this study has been the microstructural and mechanical property evolution of IN738LC during multiple reheat treatments in conjunction with long term aging. Samples of the alloy were thermally degraded at three temperatures, $760^{\circ}, 875^{\circ}$ and $950^{\circ} \mathrm{C}$, for up to 16,000 hours then reheat treated using a conventional as well as a modified reheat treatment cycles. Another series of the samples were also reheat treated after every 4,000 hours cycle (multiple reheat treatment and degradation). The rupture properties of the alloy were reassessed after every degradation and reheat treatment cycle.

The results showed that the generation of newly formed MC type carbides along the grain boundaries during reheat treatment were a major contributor to increasing the rupture lives of the degraded alloy to a value much greater than that achieved for the virgin material. However, these improved rupture lives sharply decreased with subsequent degradation at high temperatures. This drop in life was mainly related to the instability of these newly formed MC carbides which contained a high $\mathrm{Cr}$ level. However after the use of a modified reheat treatment cycle the subsequent rupture life of the alloy, determined after further ageing, was more stable. This was related to a more stable form of these newly formed MC carbides along the grain boundaries which had a lower $\mathrm{Cr}$ content.
\end{abstract}

Overall, the ultimate rupture life of the alloy was closely linked to the rate of the formation of $\mathrm{M}_{23} \mathrm{C}_{6}$ carbides and the $\gamma$ ' envelope on the grain boundaries. However, this can be controlled to an extent by the reheat treatment cycle.

\section{Introduction}

The polycrystalline superalloy IN738LC has a unique chemistry and high structural stability which provides a superior combination of mechanical properties and oxidation/corrosion resistance at high temperatures. It is still the alloy of choice for the blading of most $\mathrm{B}$ and $\mathrm{E}$ class power generation gas turbines which have aerofoil temperatures of around $750-900^{\circ} \mathrm{C}$. Since its introduction into the market in the mid 1960s many research programs have been carried out on the alloy. The effects of changes in the microstructure on the creep properties of the alloy during prolong laboratory exposure or from service running have often been investigated and reported. However the effect of interim reheat treatments on the creep properties and microstructural evolution of the alloy after prolonged exposure have not been investigated in depth, despite its widespread and longstanding commercial use during blade refurbishment.

Blades made from IN738LC may be refurbished and reheat treated 2 or 3 times within the notional design life, e.g. after every $\sim 24,000$ hours or $\sim 32,000$ hours. In addition many operators are also interested in trying to extend (through 'rejuvenating') the safe operating life of the blades using one or more refurbishment processes (and subject to an acceptable level of surface degradation). One of the main concerns is how many times a blade can reliably be refurbished and what drives the ultimate life of the blade.

This paper presents the results of an extensive study on the effect of multiple reheat treatment (of different types) and subsequent aging on the creep rupture life of the alloy. This is based on investigating the relationship between the evolution of the alloy's microstructure during extended period of aging and the associated resulting creep and rupture properties. Special attention has been paid to the decomposition and reformation of MC carbides and their role in affecting property recovery.

The decomposition of the MC carbides which supplies carbon for the formation of the $\mathrm{M}_{23} \mathrm{C}_{6}$ has been studied before [1-3]. However the effect of this decomposition on the later reheat treatment behaviour and the ultimate life of the alloy have not been considered in detail.

\section{Experimental}

Samples of the alloy (HIPed and fully heat treated) from one master heat were thermally exposed for a period of $4,000 \mathrm{~h}$ at $875^{\circ} \mathrm{C}$ and $950^{\circ} \mathrm{C}$ : some work was also done at $760^{\circ} \mathrm{C}$. The aging was also conducted for periods of $4,000 \mathrm{~h}$ under creep condition of $875^{\circ} \mathrm{C} / 90 \mathrm{MPa}$. This was followed by a reheat treatment and then further aging in 4,000 h blocks, up to a total of 16,000 hours at both of the above conditions.

Two different reheat treatment cycles were applied after each 4000 hour degradation cycle (and further degradation up to $16,000 \mathrm{~h})$.

- A standard commercial heat treatment cycle: Solution at $1120^{\circ} \mathrm{C} / 2$ hours followed by aging at $845^{\circ} \mathrm{C}$ for 24 hours

- A modified heat treatment cycle: Solution at above $1170^{\circ} \mathrm{C}$ (full gamma prime solutionising) followed by aging at $845^{\circ} \mathrm{C}$ for 24 hours

The modified reheat treatment cycle was developed based on a series of heat treatment trials in order to establish a full solutionising of the degraded microstructure of the primary $\gamma^{\prime}$ whilst also achieving grain boundaries free from a continuous network of $\mathrm{M}_{23} \mathrm{C}_{6}$ carbides formed during the aging of the alloy. The temperature of the cycle was based on the full solutionising temperature of $\gamma^{\prime}$ as indicated in the DSC graph in Figure 1 [4]. 


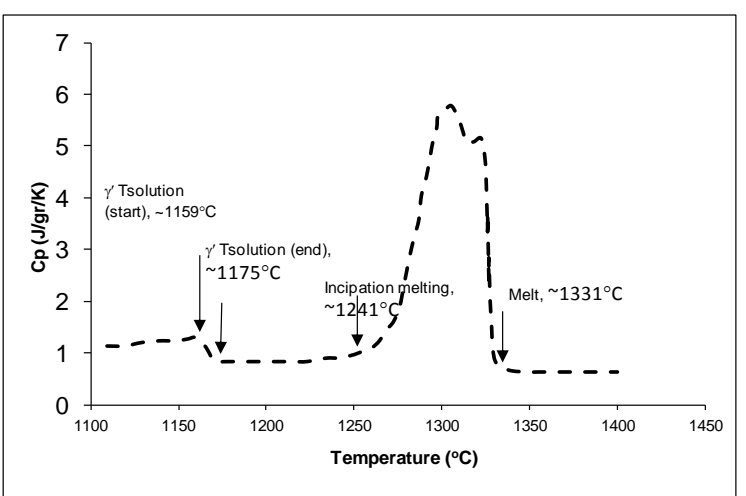

Figure 1: DSC analysis of IN738LC alloy sample with a $10^{\circ} \mathrm{C} / \mathrm{min}$ heating rate [4]

After each degradation cycle and each reheat treatment cycle the stress rupture properties were determined at two stresses, $90 \mathrm{MPa}$ for material degraded at $950^{\circ} \mathrm{C}$ and $250 \mathrm{MPa}$ for material degraded at $875^{\circ} \mathrm{C}$. This gave test lives of between $\sim 100-1000$ hours. Each dataset has then been reduced to one 'data' point with an associated scatter band using the isostress approach to permit a simple assessment of the results.

The microstructure has been investigated using optical and scanning electron microscopy (SEM) and energy dispersive spectroscopy (EDS) techniques. To develop a further understanding of the evolution of the microstructure, both gamma prime $\left(\gamma^{\prime}\right)$ and carbides ( $\mathrm{MC}$ and $\mathrm{M}_{23} \mathrm{C}_{6}$ ) phases were extracted from the test samples. The extracted particles were then examined using SEM/EDS and X-ray diffraction (XRD) techniques to develop a model which connects the specific features of the microstructure (such as carbides) to the mechanical properties.

\section{Rupture lives}

The changes in the alloy rupture lives with the aging and heat treatments have been reported before [5 and 6]. Figure 2 shows the rupture life of the alloy following a series of aging and (standard) reheat treatment cycles.

As was expected there was a marked increase in the rupture life after every reheat treatment of the degraded material. However the resilience of the improvement seen in the rupture life, after the standard reheat treatment cycle, was limited as the stress rupture life of the alloy decreased again after each additional degradation cycle (of $4,000 \mathrm{~h}$ ) following the $1^{\text {st }} 4,000 \mathrm{~h}$ cycle.

One surprising point was that the aged and then reheat treated material had much longer rupture lives than that of the virgin alloy. The possible reasons for this longer rupture lives will be discussed later.

Though there were some short term benefits from the reheat treatment, the overall trend of declining rupture lives with further degradation remained effectively the same. This decline was almost irrespective of any interim (standard) heat treatment which had been applied. This was rather surprising behaviour from the alloy but it is a very important result when relifing blades manufactured from this alloy.

The application of a modified reheat treatment cycle improved the rupture lives at both $875^{\circ}$ and $950^{\circ} \mathrm{C}$. More importantly, the decrease in the rupture lives found at the end of each subsequent degrade cycle was less than seen previously, although it had not completely prevented it.

In the long term, the modified reheat treatment has provided more stable rupture lives compared to the ones achieved by the conventional standard reheat treatment cycle.

More detail on the testing can be found in reference 5 .

Degrade History v Rupture Life

(Aged @ $950^{\circ} \mathrm{C}$, Reassessed at $990^{\circ} \mathrm{C} / 90 \mathrm{MPa}$ )

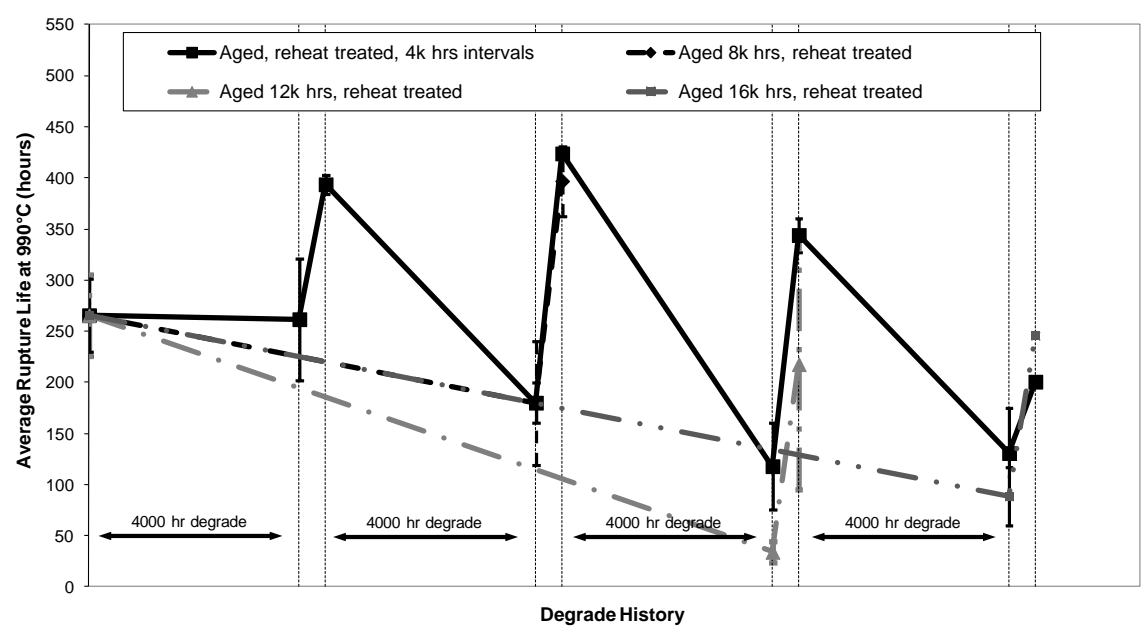

Figure 2: Rupture life of the alloy after every a series of aging at $950^{\circ} \mathrm{C}$ and (standard) reheat treatment 

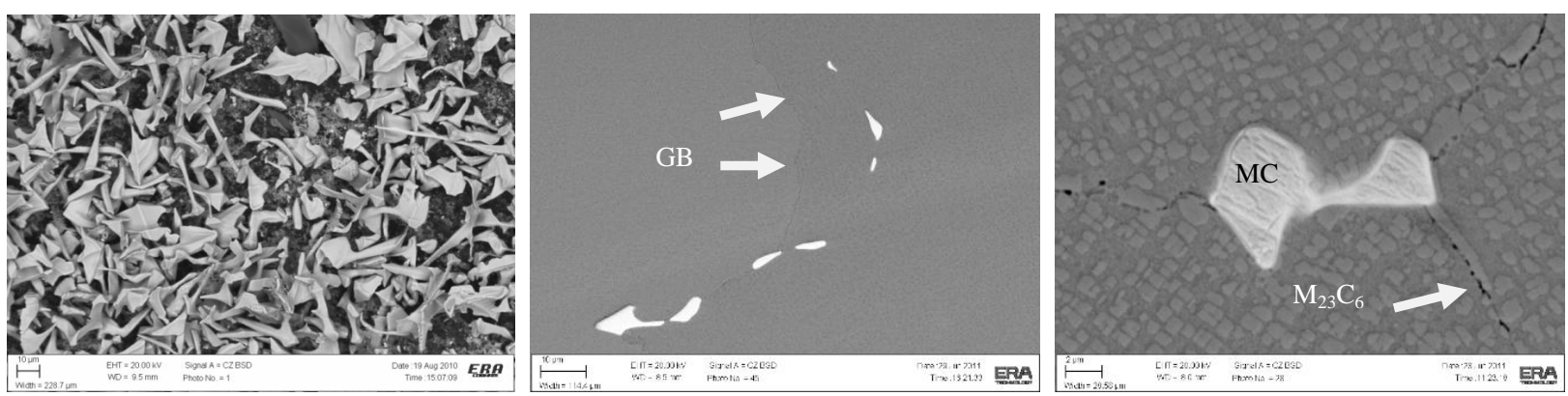

Figure 3: SEM image from the virgin IN738 LC; left: extracted carbides, mid: grain boundaries, right: small dark $\mathrm{M}_{23} \mathrm{C}_{6}$ on large $\mathrm{MC}_{\text {on }}$

Carbides evolution

\section{Carbides in the virgin alloy}

Virgin IN738LC microstructure contains large bulky MC carbides as can be seen in Figure 3. The alloy also contains a small amount of $\mathrm{M}_{23} \mathrm{C}_{6}$ carbides. About $1 \mathrm{wt} . \%$ of the alloy microstructure was formed by the carbides ( $\mathrm{MC}$ and $\mathrm{M}_{23} \mathrm{C}_{6}$ ) as measured by phase extraction. About $15-20 \%$ of the carbides were chromium carbides, confirmed by XRD analysis of the extracts. In the virgin materials the MC carbides were found on both the grain boundaries as well as inside the grains, mainly in the interdendritic regions.

In the virgin alloy the $\mathrm{M}_{23} \mathrm{C}_{6}$ carbides were very fine and mainly precipitated on the grain boundaries; i.e. fine dark precipitates seen in the back scatter image of the alloy on the grain boundaries, Figure 3 .

\section{Long aging (no interim reheat treatment)}

During long time exposure at high temperature the MC carbides decompose, both those at the grain boundaries, as well as those in the interior of the grains, forming $\mathrm{M}_{23} \mathrm{C}_{6}$ carbides. The $\mathrm{M}_{23} \mathrm{C}_{6}$ particles were relatively large and had precipitated on both the grain boundaries as well as around individual MC particles. After 16,000 hours exposure the overall amount of carbides extracted from the alloy was about $2.2 \mathrm{wt} \%$ at $875^{\circ} \mathrm{C}$ and $2.4 \mathrm{wt} . \%$ at $950^{\circ} \mathrm{C}$, a significant change from $0.9-1.1 \mathrm{wt} . \%$ measured in the virgin material. The amount of extracted carbides was about 1.3-1.6wt $\%$ at $875^{\circ} \mathrm{C}$ and $950^{\circ} \mathrm{C}$ after 8,000 hours exposure.

The XRD analysis of the extracted carbides confirms a much larger quantity of $\mathrm{M}_{23} \mathrm{C}_{6}$ carbides in the thermally degraded material. More than $65 \mathrm{wt} \%$ of the carbides in the degraded materials were $\mathrm{M}_{23} \mathrm{C}_{6}$ carbides, whilst the value was even greater for material exposed at $950^{\circ} \mathrm{C}$, reaching $83 \mathrm{wt} . \%$.

The $\mathrm{M}_{23} \mathrm{C}_{6}$ carbide size was generally larger after $950^{\circ} \mathrm{C}$ exposure relative to those seen after the $875^{\circ} \mathrm{C}$ exposures, Figure 4 . In this Figure the very large particles are remnant $\mathrm{MC}$ carbides from the virgin alloy and the small $\mathrm{M}_{23} \mathrm{C}_{6}$ particles were formed during thermal exposure. By comparing the Figure 3 (extracted carbides) and Figure 4 one can notice that a large number of $\mathrm{M}_{23} \mathrm{C}_{6}$ particles have formed after 16,000 hours exposure at $875^{\circ} \mathrm{C}$.

The precipitation of the $\mathrm{M}_{23} \mathrm{C}_{6}$ on both the grain boundaries and around the MC particles coincided with the formation of a thick envelope of $\gamma^{\prime}$ in this same region, Figure 5. The formation of this envelope can perhaps be referred to as a localised reaction zone along the grain boundaries as well as around the MC particles.

The width of the reaction zones around the particles were measured at several locations, on both grain boundaries as well as around the MC particles, using conventional image analysis software. The average, one standard deviation and the maximum measured width of the reaction zone are reported in Table 1. It was evident that by increasing the temperature and time the width of the reaction zone increased considerably, possibly in a semiexponential manner.

At $760^{\circ} \mathrm{C}$, the low temperature end studied here, the reaction mainly involved the formation of an envelope of $\gamma^{\prime}$ with only a very small amount of $\mathrm{M}_{23} \mathrm{C}_{6}$ formation. However at $950^{\circ} \mathrm{C}$, the reaction zone was fairly large and resulted in the formation of large amounts of $\mathrm{M}_{23} \mathrm{C}_{6}$ carbides. At $950^{\circ} \mathrm{C}$, most of the $\mathrm{MC}$ particles had essentially degraded, especially those with a higher surface to volume ratio.

The composition of the extracted carbides (mainly $\mathrm{M}_{23} \mathrm{C}_{6}$ ) from the thermally degraded microstructure after 8,000 hours at $875^{\circ} \mathrm{C}$ is shown in Figure 6, confirming the formation of $\mathrm{M}_{23} \mathrm{C}_{6}$ particles.

Table 1: Thickness of the reaction envelope $(\mu \mathrm{m})$ measured on the grain boundaries and around MC carbides

\begin{tabular}{|c|c|c|c|c|c|}
\hline \multirow{2}{*}{$\begin{array}{c}\mathrm{T} \\
\left({ }^{\circ} \mathrm{C}\right) \\
\end{array}$} & \multirow{2}{*}{$\begin{array}{c}\text { Measurements } \\
(\mu \mathrm{m})\end{array}$} & \multicolumn{4}{|c|}{ Exposure time (hours) } \\
\hline & & 4,000 & 8,000 & 12,000 & 16,000 \\
\hline \multirow{3}{*}{760} & Average & & 0.44 & 0.38 & 0.59 \\
\hline & STDEV & & 0.20 & 0.07 & 0.20 \\
\hline & Max & & 1.06 & 0.49 & 0.99 \\
\hline \multirow{3}{*}{875} & Average & 0.74 & 0.83 & 1.03 & 1.16 \\
\hline & STDEV & 0.22 & 0.21 & 0.26 & 0.28 \\
\hline & Max & 1.56 & 1.52 & 1.59 & 2.30 \\
\hline \multirow{3}{*}{950} & Average & 1.52 & 1.88 & 2.20 & 2.40 \\
\hline & STDEV & 0.32 & 0.35 & 0.41 & 0.50 \\
\hline & Max & 2.45 & 2.76 & 3.31 & 4.47 \\
\hline
\end{tabular}




\section{Conventional reheat treatment}

The reheat treatment of the alloy after prolong degradation significantly reduced the amount of $\mathrm{M}_{23} \mathrm{C}_{6}$ carbides in the microstructure. The amount of $\mathrm{M}_{23} \mathrm{C}_{6}$ carbides after reheat treatment (irrespective of the length of the degradation) was found to be less than $20 \mathrm{wt} \%$, a level similar to that in the virgin material.

During conventional reheat treatment, all the large $\mathrm{M}_{23} \mathrm{C}_{6}$ carbides dissolved on both the grain boundaries and around the $\mathrm{MC}$ particle. However, some fine $\mathrm{M}_{23} \mathrm{C}_{6}$ reformed during aging at $845^{\circ} \mathrm{C}$, but only along the grain boundaries.

One of the remarkable features of the microstructure after the reheat treatment was the formation of a different type of carbide along the grain boundaries, as well as around the original MC carbides. These new type carbides consisted of small elongated particles, very different from the original bulky $\mathrm{MC}$ carbides, and also from the $\mathrm{M}_{23} \mathrm{C}_{6}$ particles. These new particles had precipitated along the grain boundaries and around degraded $\mathrm{MC}$ particles, Figure 7. This creation of the new carbides (semi-MC type carbides) was observed after 4,000 hours exposure at $875^{\circ} \mathrm{C}$ and $950^{\circ} \mathrm{C}$ up to longer exposures at both temperatures. However the amount of the newly formed particles increased with exposure time and temperature.
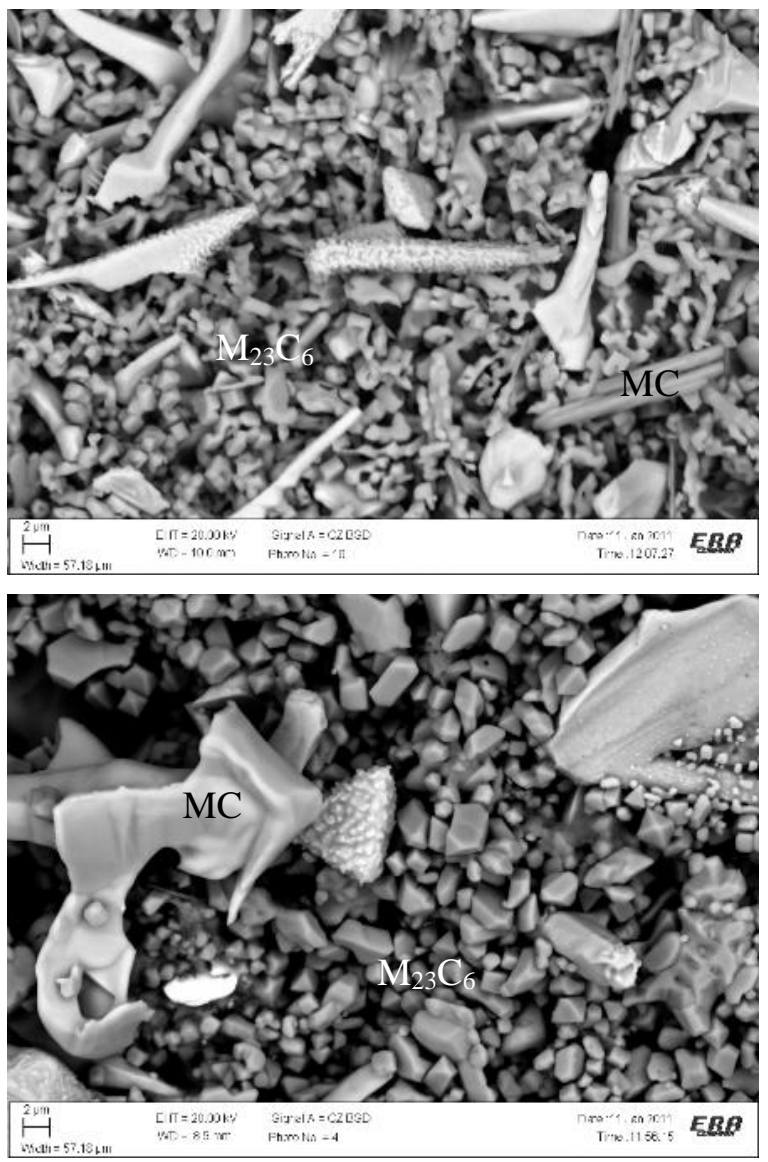

Figure 4: Formation of the $\mathrm{M}_{23} \mathrm{C}_{6}$ after 16,000 hours exposure at $875^{\circ} \mathrm{C}$ (upper) and $950^{\circ} \mathrm{C}($ lower $)$
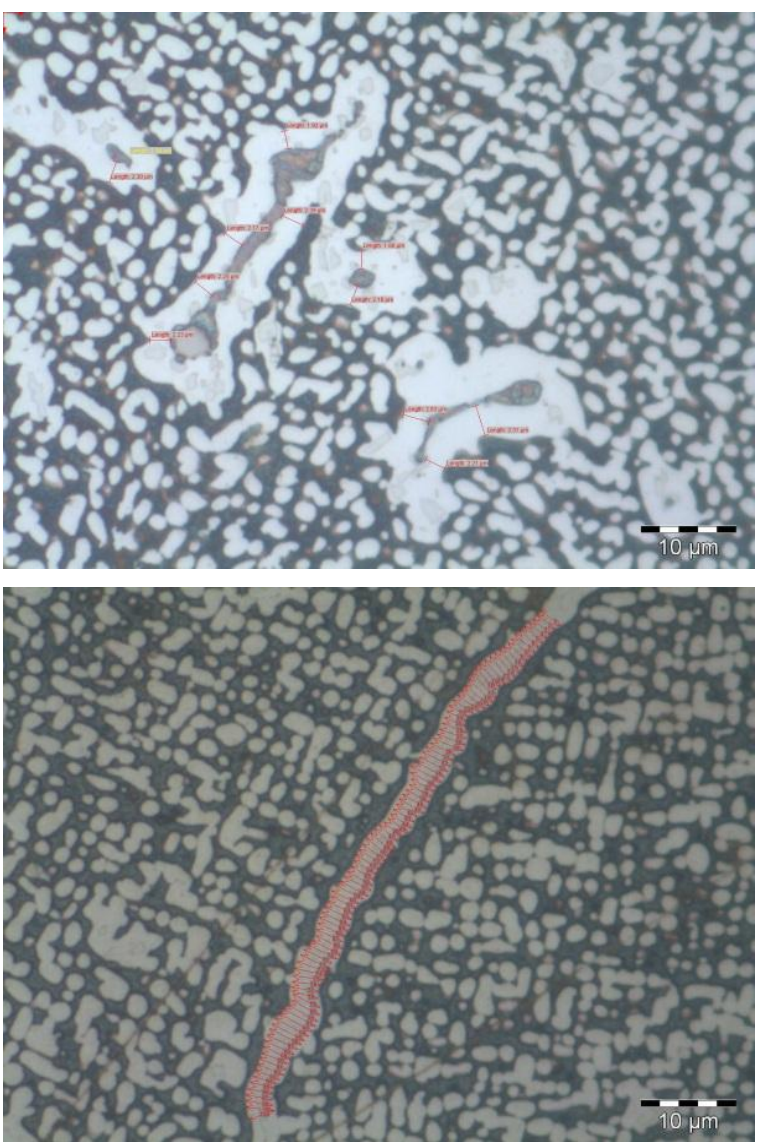

Figure 5: Measurements of the reaction zone around the MC carbides (upper) and the grain boundaries (lower)

These newly formed carbides precipitated on the grain boundaries, had a mainly MC type composition but with a high level of Cr. The composition of extracted particles after reheat treatment is shown in Figure 8 and Table 3. The EDS analysis was carried out on small elongated particles as well as one large particle (number \#3, Figure 8). It was evident that the newly formed particles have MC type composition with a high level of Ti but also with a high amount of $\mathrm{Cr}$. The analysis on the large particle, which is likely to be a remnant of an original MC particle, shows a smaller amount of $\mathrm{Cr}$. This is closer composition to the $\mathrm{MC}$ extracted from the virgin material with a $\mathrm{Cr}$ content of $\sim 1.8$ at $\%$.

This analysis, and other repeated analyses on extracted particles covering a range of exposure and reheat treatment (conventional) conditions has confirmed that the new particles reproducibly have a MC type composition with a higher level of Cr. However, these new carbides are precipitated very uniformly on the grain boundaries in the form of an unconnected chain. 


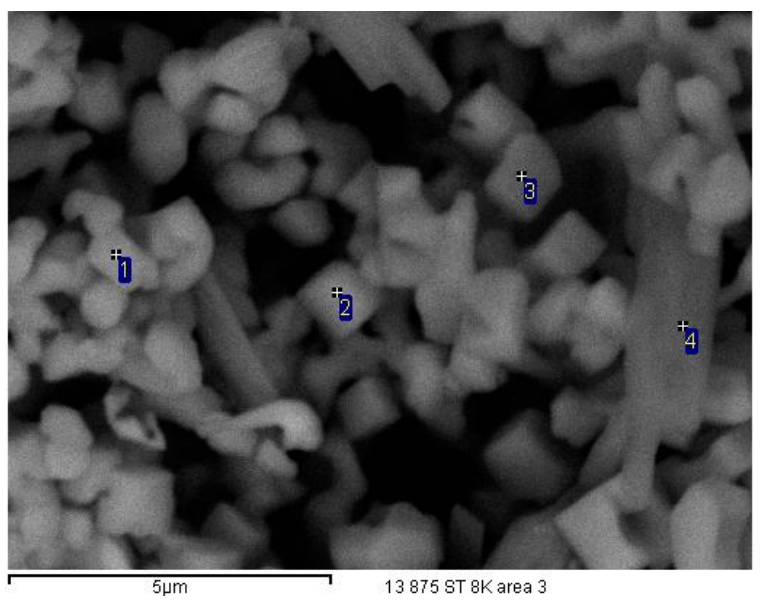

Figure 6: Extracted carbides from the alloy after 8,000 hours at $875^{\circ} \mathrm{C}$

Table 2: SEM-EDS analysis of the extracted carbide (refer to Figure 6)

\begin{tabular}{l|lllllll}
\hline Spectrum & $\mathrm{Ti}$ & $\mathrm{Cr}$ & $\mathrm{Ni}$ & $\mathrm{Nb}$ & $\mathrm{Mo}$ & $\mathrm{Ta}$ & $\mathrm{W}$ \\
& & & & & & & \\
1 & 1.77 & 90.56 & 0.70 & 0.00 & 4.66 & 0.62 & 1.70 \\
2 & 0.91 & 90.67 & 4.88 & 0.00 & 2.56 & 0.00 & 0.98 \\
3 & 1.28 & 90.56 & 1.16 & 0.00 & 5.10 & 0.00 & 1.90 \\
4 & 1.40 & 90.52 & 1.58 & 0.00 & 4.40 & 0.00 & 2.10 \\
\hline
\end{tabular}

The exact crystallographic structure of the newly formed carbides (specifically with higher $\mathrm{Cr}$ content) and the one of the virgin alloy is not known yet. Possibly further TEM work might be required.

It should be stressed that these newly formed MC type particles were totally different from the reformed fine $\mathrm{M}_{23} \mathrm{C}_{6}$ particles formed during the $845^{\circ} \mathrm{C} / 24$ hours ageing heat treatment of the alloy, Figure 9.

One of the key differences between the microstructure of the alloy with interim reheat treatments and one without any interim reheat treatment concerned the quantity of decomposed original $\mathrm{MC}$ carbides and newly regenerated MC type carbides. In the alloy with the interim reheat treatments, a more extensive degree of degradation of the original MC carbides was visible, Figure 10. In addition, a larger population of the newly reformed MC type carbides was also detected in the material with interim reheat treatments. This may be partly related to exposing a fresh surface of the remnant original MC to the matrix after each interim reheat treatment, i.e. the interim reheat treatment somehow accelerated the decomposition of the original MC particles. Whereas in the continues exposure regime the $\mathrm{MC}$ was covered by an envelope of the $\gamma^{\prime}$ and $\mathrm{M}_{23} \mathrm{C}_{6}$ which probably limited further diffusion driven reaction of the $\mathrm{MC}$ with the gamma matrix and hence reducing the degradation rate of the MC.
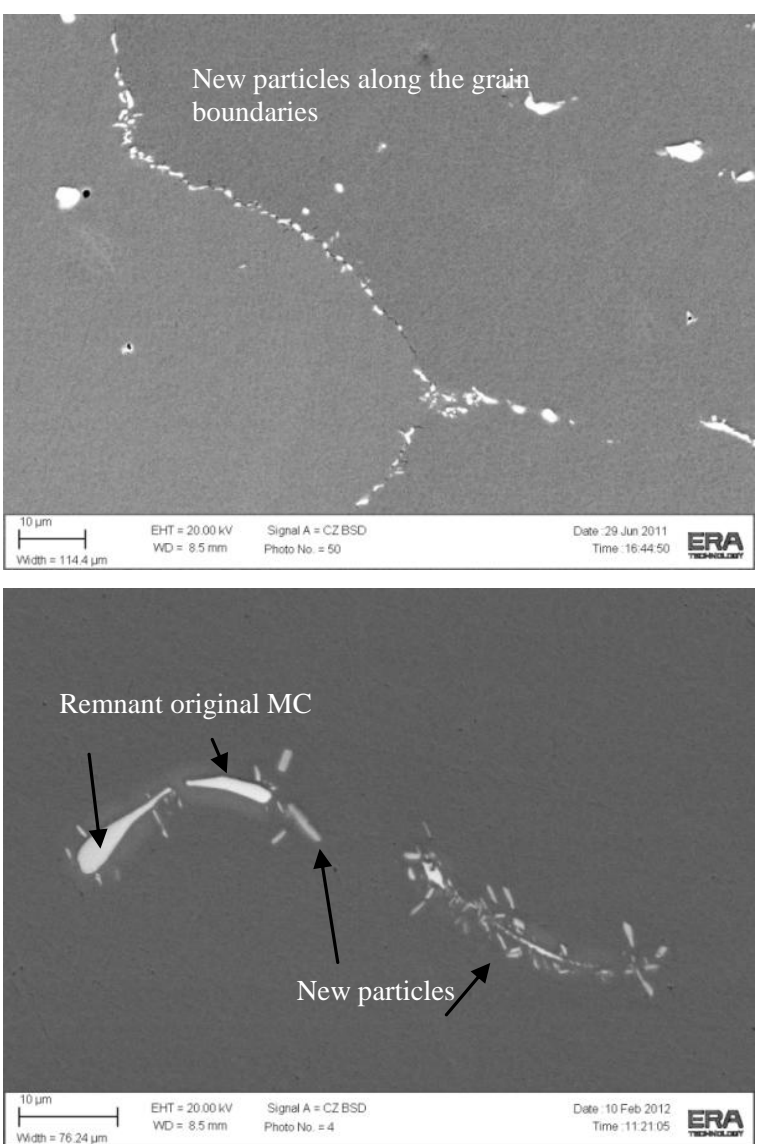

Figure 7: Newly formed MC type carbides on the grain boundaries and around MC particles, after reheat treatment from; upper: 8,000 hours $/ 875^{\circ} \mathrm{C}$ (with one interim heat treatment), lower: 16,000 hours $/ 950^{\circ} \mathrm{C}$ (no interim heat treatment)

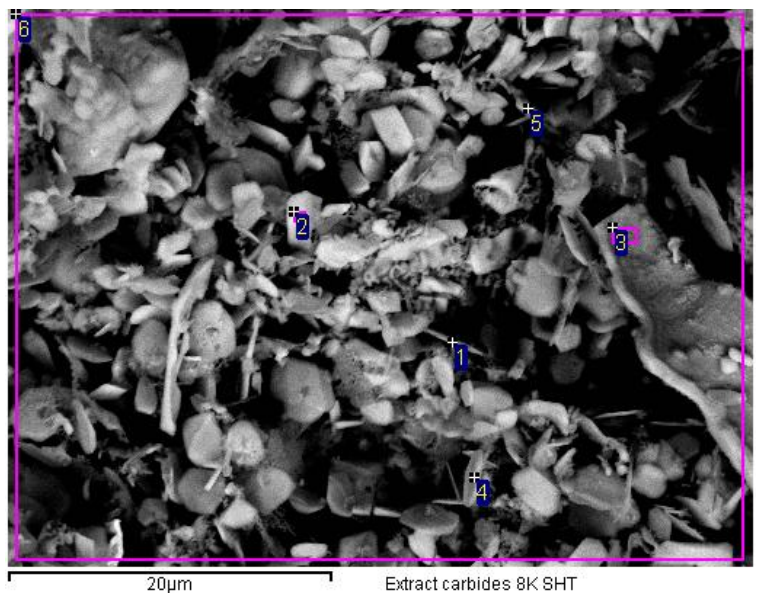

Figure 8: Extracted carbides from the reheat treated alloy after 8,000 hours exposure at $950^{\circ} \mathrm{C}$ 
Table 3: Composition of the particles in Figure 8

\begin{tabular}{l|lllllll}
\hline Spectrum & $\mathrm{Ti}$ & $\mathrm{Cr}$ & $\mathrm{Ni}$ & $\mathrm{Nb}$ & $\mathrm{Mo}$ & $\mathrm{Ta}$ & $\mathrm{W}$ \\
& & & & & & & \\
1 & 42.8 & 25.0 & 0.8 & 6.7 & 2.8 & 15.7 & 6.2 \\
2 & 46.3 & 13.9 & 0.0 & 13.1 & 3.3 & 18.6 & 4.7 \\
3 & 57.6 & 7.3 & 0.0 & 9.7 & 3.5 & 18.5 & 3.4 \\
4 & 40.6 & 24.9 & 0.0 & 13.2 & 3.3 & 13.0 & 5.1 \\
5 & 54.6 & 27.3 & 0.0 & 6.1 & 2.8 & 6.5 & 2.6 \\
6 & 42.2 & 24.9 & 1.4 & 10.7 & 2.8 & 13.8 & 4.3 \\
\hline
\end{tabular}

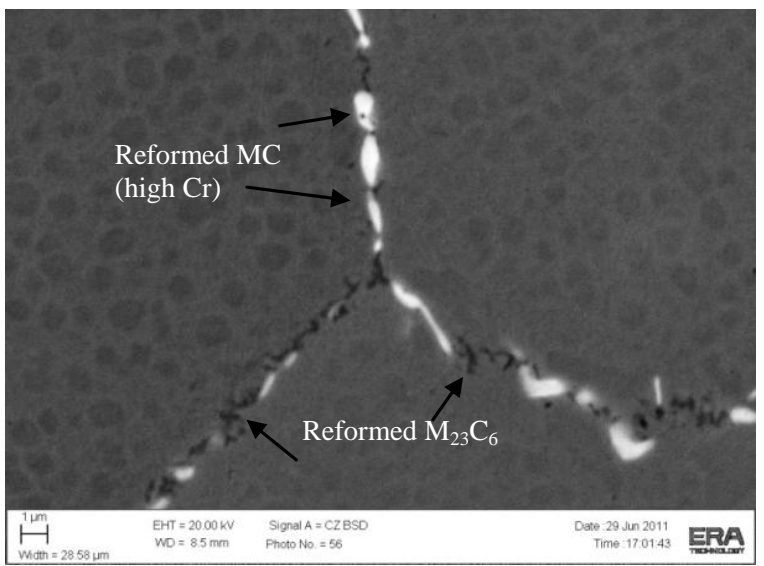

Figure 9: Newly formed MC (bright particles) and reformed fine $\mathrm{M}_{23} \mathrm{C}_{6}$ (dark particles) after aging at $845^{\circ} \mathrm{C} / 24$ hours

\section{Modified reheat treatment}

The microstructure after the modified reheat treatment also showed the formation of a large quantity of fine new particles along the grain boundaries, as well as around the original MC particles, Figure 11. Newly formed particles along the grain boundaries were generally larger than the one detected after the conventional heat treatment. In addition, the new particles were more bulky than the small elongated ones seen after the conventional reheat treatment.

SEM-EDS analysis results, in Figure 12 and Table 4, shows that the newly formed carbides had a composition closer to the original MC. These newly formed particles had much lower level of chromium and were very close to the composition of the virgin alloy (less than 4-5 at\% Cr). In the modified heat treatment some of the newly formed MC had lesser amount of Ta, the darker particles in Figure 12.

The XRD results of the extracted carbides showed that the overall amount of $\mathrm{Cr}_{23} \mathrm{C}_{6}$ was lower after an interim modified reheat treatment than was the case after a conventional treatment (both had same exposure of up to 12,000 hours). This could mean that newly formed carbides in the modified heat treated samples are more stable.
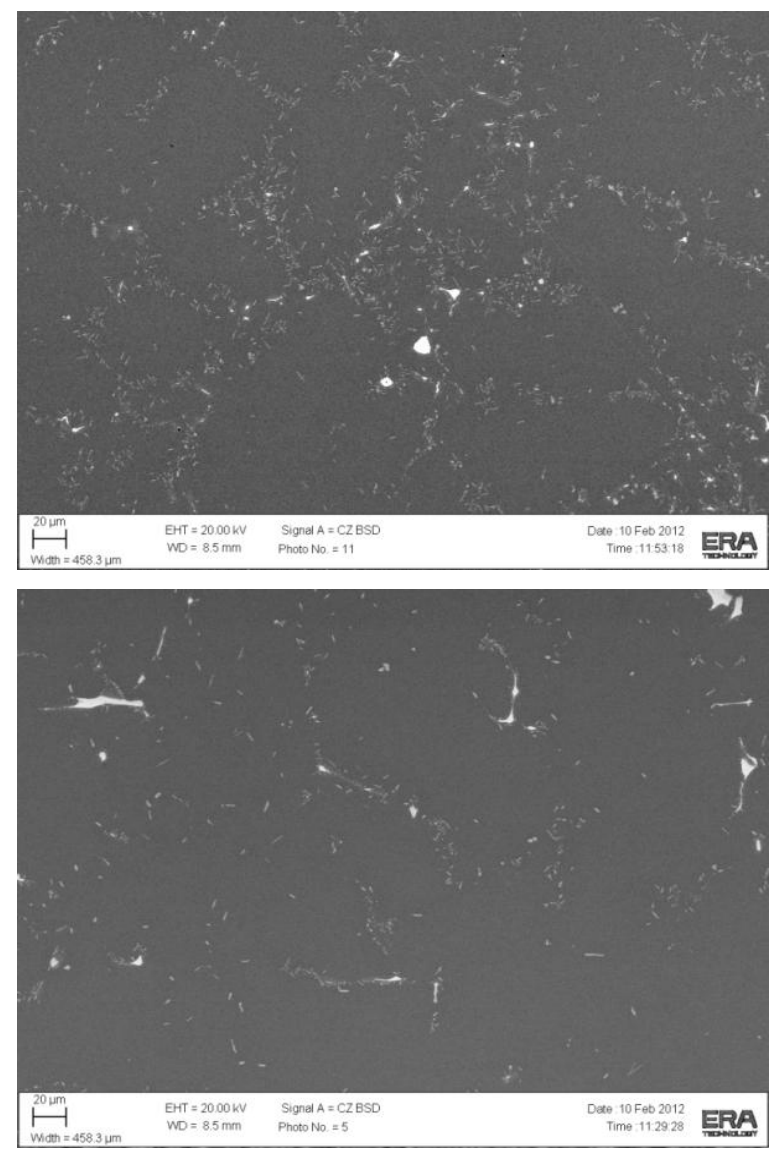

Figure 10: Newly formed MC type carbides after 16,000 hours exposure at $950^{\circ} \mathrm{C}$ with interim reheat treatment (after every 4,000 hours exposure) and without any interim reheat treatment (lower)

\section{$\underline{\text { Carbides in a reheat treated blade }}$}

Decisions on repairability and further use of a blade are largely dependent on the surface condition and the microstructural degradation of the blade. The recovery of the degraded microstructure is closely linked to the reheat treatment used during the refurbishment process.

The microstructure of a row 2 blade made of IN738LC from a 40MW turbine which had been in service for 22,000 hours after a previous repair cycle (a total operation of $\sim 44,000$ hours) was investigated, Figure 13. The microstructure after a second repair and reheat treatment (using the conventional approach) is shown in Figure 14. It was found that the hotter parts of the blade (at $75 \%$ span) near to the leading edge had a microstructure which contained the same newly formed MC-type carbides along the grain boundaries. These were very similar to the ones observed after the conventional reheat treatment of the thermally degraded laboratory samples described above. However, in the cooler sections, close the radial cooling holes, no sign of the newly formed particles could be seen, and the microstructure of the grain boundaries was very similar to that of the original material. 

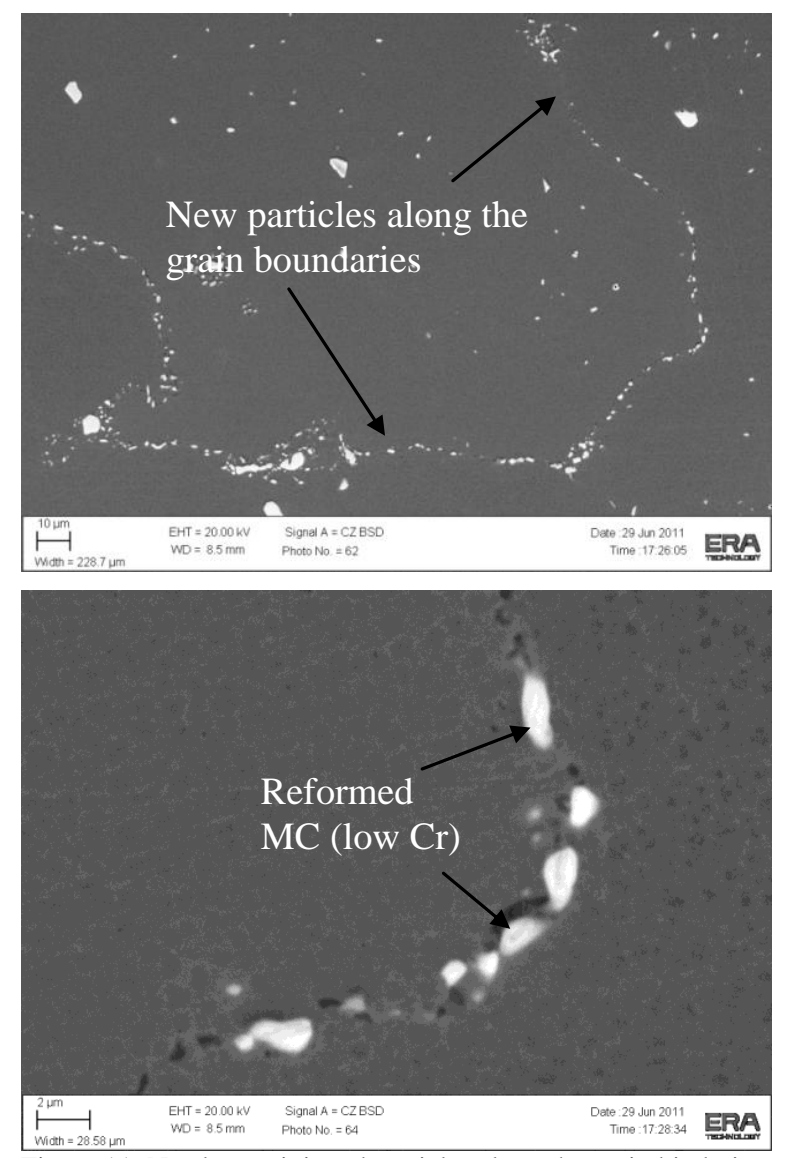

Figure 11: Newly precipitated particles along the grain binderies after modified reheat treatment of the sample with 8,000 hours exposure at $875^{\circ} \mathrm{C}$

\section{Gamma Prime}

The degradation of the gamma prime has been reported in detail previously [5 and 6]. After a conventional reheat treatment, i.e. a subsolvus 'solutionising' temperature, a large quantity of the coalesced $\gamma^{\prime}$ particles (formed during the thermal exposure) have remained and have not been recovered by the conventional reheat treatment, especially for those samples with the longest exposures, Figure 15. This was not the case after the modified (supersolvus) heat treatment. The alloy then had a microstructure with a fully recovered $\gamma^{\prime}$ microstructure [5].

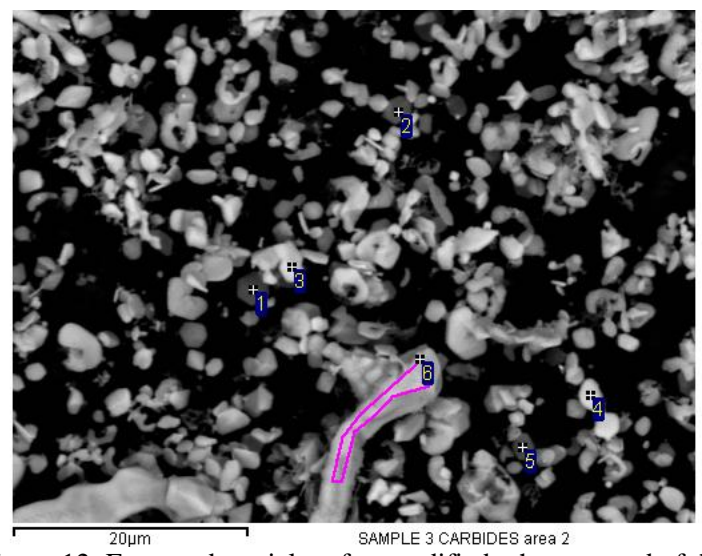

Figure 12: Extracted particles after modified reheat treated of the thermally degraded alloy at $950^{\circ} \mathrm{C} / 8,000$ hours (with one interim reheat treatment at 4,000 hours)

Table 4: EDS results of the particles from Figure 12

\begin{tabular}{l|lllllll}
\hline Spectrum & Ti & Cr & Ni & Nb & Mo & Ta & W \\
1 & & & & & & & \\
2 & 50.95 & 3.27 & 0.00 & 18.04 & 5.29 & 15.53 & 6.92 \\
3 & 53.38 & 1.55 & 0.00 & 17.58 & 5.03 & 16.04 & 6.41 \\
4 & 50.60 & 1.35 & 0.00 & 17.21 & 0.00 & 27.19 & 3.65 \\
5 & 51.26 & 2.26 & 0.00 & 16.49 & 0.00 & 27.22 & 2.77 \\
6 & 41.96 & 2.49 & 1.24 & 19.27 & 4.58 & 14.55 & 5.91 \\
& 47.79 & 6.12 & 0.56 & 16.29 & 1.88 & 24.10 & 3.25 \\
\hline
\end{tabular}

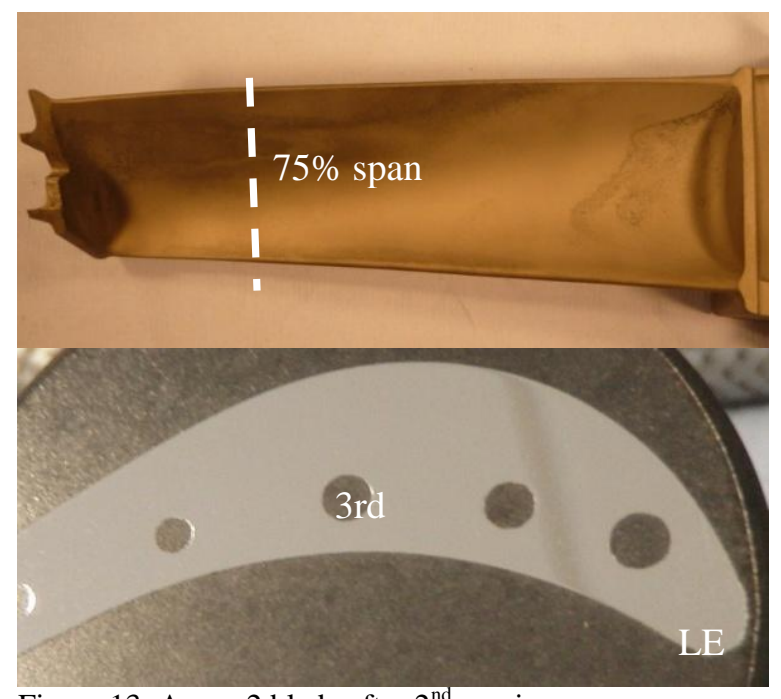

Figure 13: A row 2 blade after $2^{\text {nd }}$ repair 

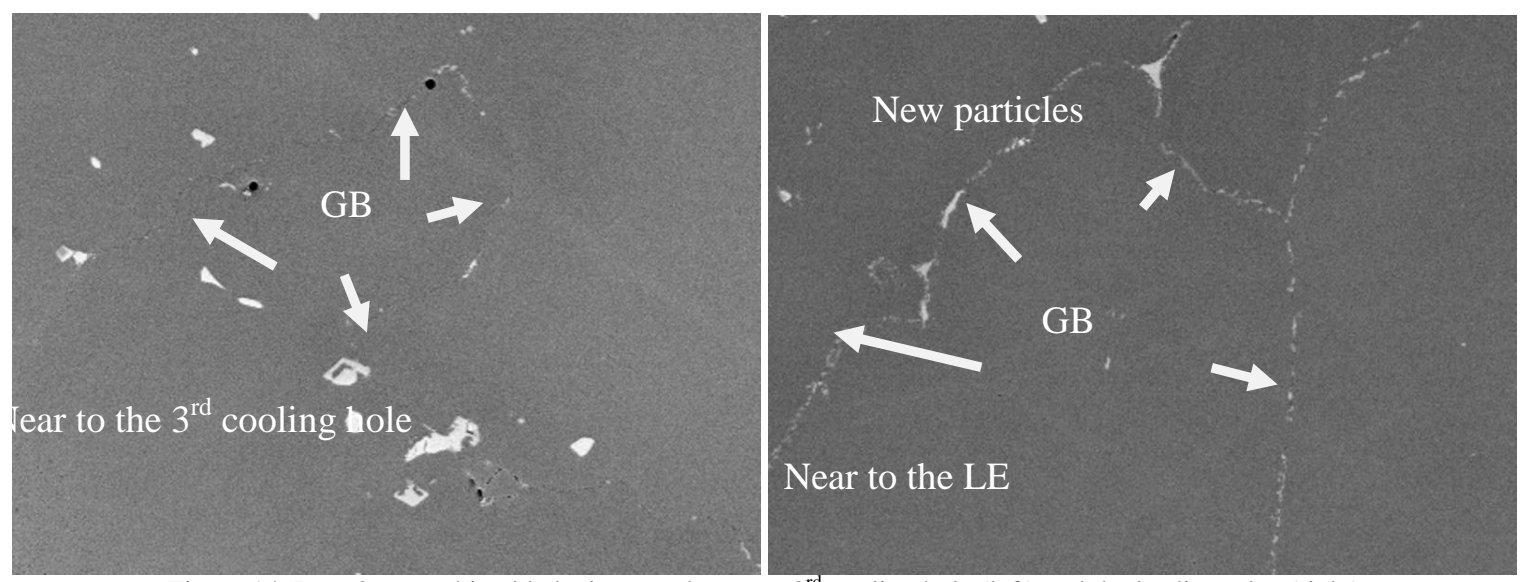

Figure 14: Row 2 gas turbine blade, image taken near $3^{\text {rd }}$ cooling hole (left) and the leading edge (right)
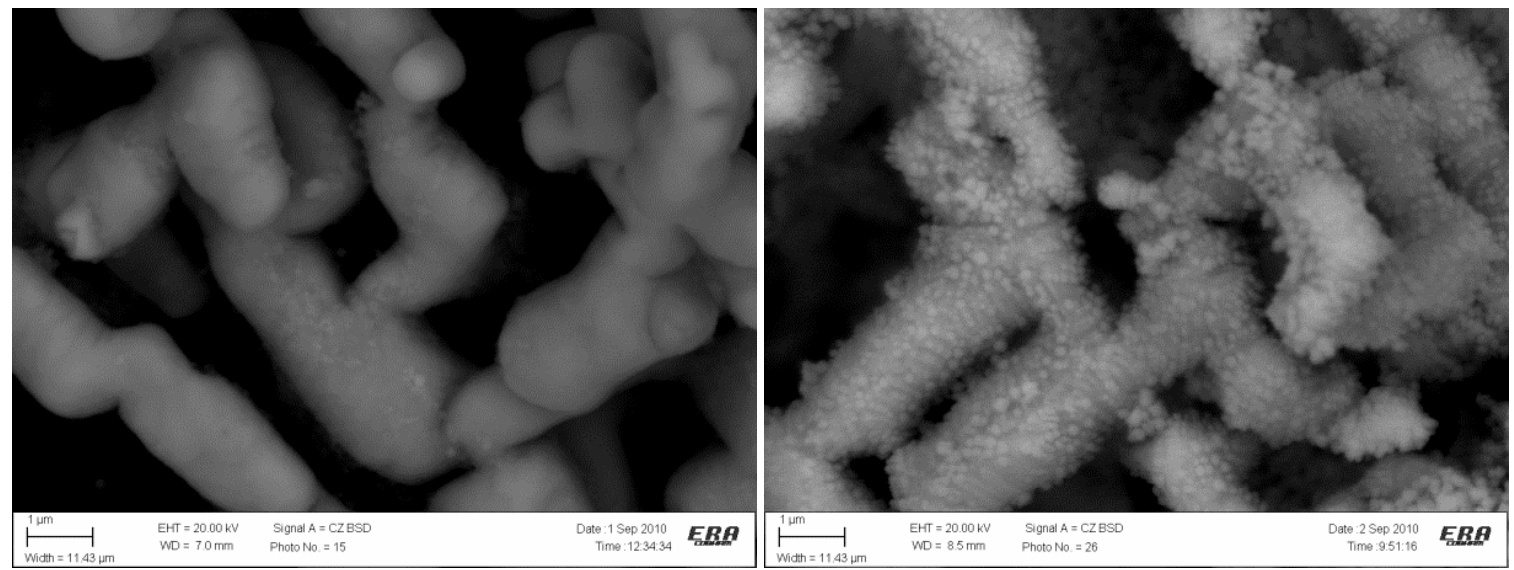

Figure 15: Microstructure of coalesced $\gamma^{\prime}$ after 16,000 hours at $950^{\circ} \mathrm{C}$ (left) and after conventional reheat treatment (right)

\section{Rupture life and reheat treatments}

The rupture life of the alloy is closely linked to the condition of the microstructure. It was seen that after thermal exposure, hence changes in the alloy microstructure, there was a sharp drop in the rupture lives, which was expected. However a reheat treatment of the degraded alloy apparently recovered the rupture life of the alloy to a level which was higher than that of the virgin material. One could think that the reheat treatment has markedly increased the rupture life, and hence the expected service life of the alloy, and that the reheat treatment and rejuvenation had been very successful. This finding is not confirmed by this current study.

The subsequent degradation behaviour showed that the recovered lives were not maintained, particularly for the conventional heat treatment case. To the contrary, the work shows that subsequent lives decreased rapidly.

This means that the improved rupture lives were very short lived and declined sharply with further thermal exposure. More importantly, there was no significant difference in the overall decline in rupture lives of the alloy with or without any interim conventional reheat treatments.
In the case of a modified reheat treatment, an increase of the rupture lives after reheat treatment was also obtained. However the subsequent drop in the lives with further thermal exposure was relatively less than that was seen in the case after the conventional reheat treatment.

One of the key microstructural features which contributed to an increased rupture life (significantly above that for the virgin material) after thermal exposure and reheat treatment, is considered to be the presence of the newly formed small MC type carbides along the grain boundaries. The recovered $\gamma^{\prime}$ particles may also improve the rupture lives but not to the extent that the properties are much higher than that for the virgin material.

Similarly the sharp drop in the rupture lives after further exposure is also related to the rate of formation of the continues network of $\mathrm{M}_{23} \mathrm{C}_{6}$ particles with a $\gamma^{\prime}$ envelope on the grain boundaries. It is clear from this current study that regenerated particles formed during the conventional reheat treatment were $\mathrm{MC}$ type carbides but with a higher level of $\mathrm{Cr}$ (probably a less stable MC). The higher $\mathrm{Cr}$ content, and the smallness of the particles which were positioned on the grain boundaries, may drive a faster decomposition rate of these new MC type carbides and the 
subsequent reformation of $\mathrm{M}_{23} \mathrm{C}_{6}$ hence leading to a sharp drop in life after further exposure.

The exact mechanism of creep deformation in the presence of these newly formed small MC type carbides along the grain boundaries are not known yet. Further TEM work is necessary to understand this better. The thermodynamic stability of the new $\mathrm{MC}$ with higher $\mathrm{Cr}$ content would also be an important study in order to predict its stability at high temperature.

An important point in terms of relifing a blade is that the short term recovery of the alloy depends on the level of carbide reprecipitation as well as the recovery of the $\gamma^{\prime}$ microstructure during the reheat treatment. However the long term properties of IN738LC are strongly connected to the extent of decomposition of the MC carbides. It is clear that the alloy's microstructure cannot be returned to that of the virgin condition. However it seems that the type and morphology of the newly formed MC particles along the grain boundaries are important when considering the properties of the material, and therefore the operational life of blades. Nevertheless the ultimate life of the blade alloy may be controlled by rate of formation of the network of $\mathrm{M}_{23} \mathrm{C}_{6}$ in an envelope of $\gamma^{\prime}$, which is depended to the stability of the newly formed MC.

Overall, the modified heat treatment provides a structure which has a lower rate of subsequent $\mathrm{M}_{23} \mathrm{C}_{6}$ formation relative to that after a conventional reheat treatment. The amount of $\mathrm{M}_{23} \mathrm{C}_{6}$ measured after further exposure of the modified reheat treated samples was lower than was found with material given the conventional reheat treatment cycle. This could be one of the reasons for the greater stability and more gradual drop in the properties with further exposure.

The evolution in the alloy microstructure during thermal exposure and its recovery during subsequent reheat treatment forms an IN738LC microstructure which is really different from that of the original material. This is a key aspect to assessing the potential performance of a blade which has been in service and needs to be repaired and reheat treated.

\section{Conclusion}

In this study the recovery of the thermally exposed microstructure of IN738LC and its effect on the alloy's rupture life has been examined. The results can be summarised as:

- After thermal exposure and reheat treatment the microstructure is different from that of virgin IN738LC because of the formation of new small MC type particles on the grain boundaries.

- The formation of these new MC type carbides on the grain boundaries after a conventional or modified reheat treatment, is one of the main reason for achieving a rupture lives which exceed those the virgin alloy.

- The newly reformed MC type carbides produced by a conventional reheat treatment contain a higher $\mathrm{Cr}$ content than those produced by a modified reheat treatment.
- The sharp drop in the alloy rupture life after subsequent thermal exposure was related to the fast decomposition of the newly formed small MC type carbides on the grain boundaries with higher $\mathrm{Cr}$ content.

- A greater stability of the rupture lives after exposure of the material given a modified reheat treated was related to the formation of a more stable MC type carbide on the grain boundaries with a lower $\mathrm{Cr}$ content.

- The ultimate life of the material is limited to the rate of formation of $\mathrm{M}_{23} \mathrm{C}_{6}$ and its $\gamma^{\prime}$ envelope along the grain boundaries. This is now a function of the total amount of decomposed MC as well as the type of new MC carbide reformed on the grain boundaries by the specific reheat treatment cycle.

\section{Acknowledgement}

Some of this work was funded by Siemens AG, Siemens Westinghouse, Siemens Industrial Turbines, PX Ltd, Laborelec, Elsam, Vattenfall and EDF.

\section{References}

1. Y. Yoshioka, D. Saito, K. Fujiyama, and N. Okabe, Effect of materials degredation on mechanical properties of cast Ni-base superalloys IN738LC, page 53-58, in proceeding of Advanced materials and coatings for combustion turbine, edited by V.P. Swaminathan and N.S. Cheruvu, Published by ASM, 1994.

2. D. Murkherji, F. Jiao, W. Chen and R.P Wahi, Deformation behaviour and microstructural evolution in IN738LC creep and tensile properties, pp 1067-1076, in proceeding of High temperature materials for power engineering, edited by Klumar et al, 1990.

3. G. Lvov, V.I. Levit and M.J. Kaufman, "Mechanism of primery MC crabide decomposition in Ni-Base Superalloy", Metallurgical Transaction. A, 2004, volume 35A, pp 1669-1679.

4. L. A. Chapman, "Application of high temperature DCS system to Ni-Base superalloy", Journal of Materials Science, Issue 39 (2004) pp 7229 - 7236.

5. S. Pahlavanyali, M. Wood, G. Marchant, "Microstructural evolutions of IN738LC during multiple reheat treatment and aging", in Parsons Conference 2011, September 2011, Portsmouth UK. Published by IOM3, October 2011.

6. M. Wood, "The effect of blade superalloy reheat treatment", VGB PowerTech., Volume 11, 2011, pp74 78. 